\title{
BIOPULPING PELEPAH TANAMAN SALAK MENGGUNAKAN JAMUR PELAPUK PUTIH PHANEROCHAETE CHRYSOSPORIUM
}

\author{
Triastuti Rahavu, Aminah Asngad, Suparti \\ Prodi Pendidikan Biologi FKIP UMS \\ tr124@ums.ac.id
}

\begin{abstract}
Abstrak-Serat pelepah tanaman salak yang menjadi limbah perkebunan salak di Kabupaten Sleman Yogyakarta sama sekali belum dimanfaatkan dan menjadi sampah/limbah padahal mengandung selulosa $42 \%$. Tujuan penelitian ini adalah untuk mengetahui pengaruh JPP (Jamur Pelapuk Putih) $P$. chrysosporium pada proses biopulping serat pelepah salak. Rancangan penelitian menggunakan RAL 1 faktor yaitu jenis inokulum ( $\mathrm{J} 0=$ kontrol, $\mathrm{J} 1=$ P.chrysosporium). Pelepah tanaman salak dicacah dengan pencacah sampah kemudian disterilkan dalam autoclave selama 45 menit pada suhu $121^{\circ} \mathrm{C}$. Serpih pelepah salak (150 g berat kering) dimasukkan ke dalam kantong plastik tahan panas kemudian diinokulasi $10 \%$ inokulum jamur dan diinkubasi dalam suhu ruang $\left(29-30^{\circ} \mathrm{C}\right)$ selama 45 hari. Serpih pelepah tanaman salak yang telah diinkubasi sampai masa inkubasi berakhir dimasak dengan $\mathrm{NaOH}$ $10 \% \mathrm{~L}: \mathrm{W}=1: 5$ (L=berat serpih, $\mathrm{W}=$ larutan pemasak), lama pemasakan 1 jam. Setelah dimasak, serpih direndam dalam air dingin $1 \mathrm{~L}$ selama 24 jam untuk mengoptimalkan sisa-sisa bahan pemasak dalam melunakkan serpih. Selanjutnya serpih dicuci sampai bebas alkali dan diblender menjadi serbuk untuk analisis bilangan Kappa dan kadar holoselulosa. Hasil penelitian menunjukkan bahwa P.chrysosporium dapat tumbuh bagus pada substrat serat pelepah salak untuk biopulping dan dapat menurunkan bilangan Kappa 5\% setelah 45 hari inkubasi tetapi kadar holoselulosa sama dengan kontrol.
\end{abstract}

Kata kunci: biopulping, jamur pelapuk putih, pelepah salak, Phanerochaete chrysopsorium

\section{PENDAHULUAN}

Penggunaan kertas di dunia saat ini telah mencapai angka yang sangat tinggi. Berdasarkan data Kementerian Perindustrian Republik Indonesia, pada tahun 2012 permintaan kertas mencapai 12 juta ton. Zulfikar (2011) mengemukakan 90\% pulp dan kertas yang dihasilkan menggunakan bahan baku kayu sebagai sumber bahan berserat selulosa. Maka dapat diprediksikan bahwa akan terjadi eksploitasi hutan secara besar-besaran yang dapat mengakibatkan terganggunya kestabilan lingkungan sehingga perlu mendapat perhatian khusus. Untuk mengatasi hal ini pemerintah harus mencari alternatif untuk mengganti penggunaan kayu hutan sebagai bahan baku pembuat pulp dan kertas.

Bahan alternatif yang sudah digunakan antara lain jerami dengan kadar selulosa 30,2\%, ampas tebu dengan kadar selulosa 43-52\% (Nasution, 2010), mendong (Kuntari, 2010), kulit singkong dan bulu ayam (Nurjannah dan Asngad, 2015), bulu ayam dan kulit kacang (Riyanti dan Asngad, 2015), kulit jagung dan bulu ayam (Pratiwi dan Asngad, 2015). Serat tanaman yang potensial dan belum dimanfaatkan adalah serat pelepah tanaman salak.

Tanaman salak merupakan komoditi utama Kabupaten Sleman Yogyakarta. Kepala Bidang Tanaman Pangan dan Hortikultura Dinas Pertanian, Perikanan, dan Kehutanan (DPPK) Kabupaten Sleman Edi Sriharmanto, mengatakan luas lahan salak di Sleman mencapai 2.500 hektar. Pemanfaatan tanaman salak selama ini hanya terfokus pada buahnya saja, sedangkan untuk pelepah dan daunnya belum termanfaatkan secara baik. Pelepah tanaman salak yang telah dipotong dianggap masyarakat sebagai limbah dan belum termanfaatkan, sehingga apabila dibuang ke sungai akan 
merusak lingkungan dan menurunkan fungsi sungai sebagai saluran air. Menurut informasi dari Ketua Asosiasi petani salak di Sleman Yogyakarta, bahwa tanaman salak harus disiangi pelepahnya setiap enam bulan sekali. Dalam satu rumpun tanaman salak produktif setiap tahunnya mampu menghasilkan potongan pelepah salak kurang lebih sekitar 24 buah. Apabila dikalkulasikan dengan jumlah tanaman salak yang ada, maka dalam satu tahun pelepah salak yang belum termanfaatkan sekitar \pm 23.000 truk. Serat pelepah tanaman salak ini memiliki potensi yang cukup menjanjikan untuk bahan baku kertas seni karena mengandung 42,54\% selulosa, 34,35\% hemiselulosa dan 28,01\% lignin (Raharjo, dkk., 2016).

Bahanutama dalam proses pembuatan kertas adalah bubur kertas (pulp). Proses pembuatan pulp ada dua macam yaitu secara kimia (chemical pulping) dan proses mekanikal (mechanical pulping). Pulping secara kimia memberikan dampak negatif bagi lingkungan, sehingga beberapa peneliti mencoba melakukan proses pulping secara biologi (biopulping) menggunakan jamur pelapuk putih (JPP) (Bajpai, 2012). JPP hanya akan mendegradasi lignin dari bahan serat alam dan tidak atau sedikit mendegradasi selulosa (Bajpai, 2012) karena kelompok jamur ini mempunyai enzim lignin peroksidase (Isroi et al. 2011). Dari banyak spesies JPP, $P$. chrysosporium mampu mendegradasi lignin untuk hardwoods dan softwood (Kang, 2007).

Pada penelitian ini akan digunakan JPP P. chrysosporium untuk biopulping pelepah tanaman salak. Banyak faktor yang berpengaruh terhadap proses biopuling di antaranya jenis JPP, lama inkubasi, bentuk dan konsentrasi inokulum, konsentrasi $\mathrm{NaOH}$, dan jenis substrat. Tujuan penelitian ini adalah untuk mengetahui pengaruh JPP $P$. chrysosporium pada proses biopulping serat pelepah salak.

\section{METODE PENELITIAN}

\section{Alat dan Bahan Penelitian}

a. Alat: timbangan analitik, bejana pemasak, erlenmeyer 1 L, gelas ukur, penyaring, blender, alat pemotong, kompor, autoklaf, LAF (Laminar Air Flow), kulkas, petridisk, ose, tabung reaksi, oven, mikropipet, lampu spiritus.

b. Bahan: Pelepah tanaman salak (dari Sleman Yogyakarta), $\mathrm{NaOH}$ teknis, kultur P.crysosporium, media PDA (Potato Dextrose Agar), medium JIS Broth, $\mathrm{KH}_{2} \mathrm{PO}_{4^{\prime}}$ $\mathrm{MgSO}_{4} .7 \mathrm{H}_{2} \mathrm{O}$, glukosa, pepton, dan malt extract, akuades, alkohol, spiritus.

\section{Persiapan Bahan Baku (Fatriasari dkk., 2010)}

Pelepah tanaman salak tanpa kulit yang digunakan adalah tanaman salak dari Kecamatan Turi Kabupaten Sleman Yogyakarta. Pelepah tanaman salak dibuat serpih berukuran $\pm 1,6 \mathrm{~cm}$ dengan pencacah sampah selanjutnya dikeringkan sampai berat kering konstan. Sebelum disterilisasi, serpih direndam dalam akuades 1:1 selam 24 jam. Selanjutnya ditiriskan dan diatur kelembaban $70 \%$ kemudian dimasukkan ke dalam plastik tahan panas @ $150 \mathrm{~g}$ berat kering. Sterilisasi dilakukan dua tahap yaitu dengan dikukus selama 30 menit dilanjutkan dengan autoclave selama 30 menit pada suhu $121^{\circ} \mathrm{C}$.

\section{a. Persiapan Inokulum (Fatriasari dkk., 2010)}

Biakan JPP P.crysosporium dikultur pada medium PDA selama 7-14 hari. Sebanyak $5 \mathrm{ml}$ medium JIS Broth dimasukkan ke dalam masing-masing agar miring, jamur kemudian 
dirontokkan dengan ose. Suspensi tersebut kemudian dituang ke dalam $45 \mathrm{ml}$ medium JIS Broth (dalam $1 \mathrm{~L}$ aquades ditambahkan $3 \mathrm{~g} \mathrm{KH}_{2} \mathrm{PO}_{4^{\prime}} 2 \mathrm{~g} \mathrm{MgSO}_{4} .7 \mathrm{H}_{2} \mathrm{O}, 25 \mathrm{~g}$ glukosa, $5 \mathrm{~g}$ pepton, dan $10 \mathrm{~g}$ malt extract) dan diinkubasi selama 7-8 hari dalam kondisi stasioner. Sebanyak $5 \mathrm{~mL}$ corn steep liquor dituangkan ke dalam $50 \mathrm{ml}$ inokulum (10\% inokulum stock). Inokulum dihomogenkan dengan smart blender dengan kecepatan tinggi selama dua kali 20 detik. Campuran ini dinamakan inokulum stok.

b. Metode Inokulasi (Fatriasari dkk., 2010)

Serpih pelepah salak (150 berat kering oven/BKO) dimasukkan ke dalam kantong plastik tahan panas. Ada 2 kelompok perlakuan yaitu pertama : kontrol (tanpa jamur pelapuk putih), 2. Inokulasi dengan P.chrysosporium. Total inokulum cair yang dinjeksikan secara merata dalam serpih pelepah tanaman salak adalah 15 ml. Serpih pelepah tanaman salak dalam kantong plastik kemudian diinkubasi dalam suhu ruang (29$30^{\circ} \mathrm{C}$ ) selama 30 dan 45 hari.

c. Pembuatan dan Pengujian Pulp (Fatriasari dkk., 2010)

Serpih pelepah tanaman salak yang telah diinkubasi sampai masa inkubasi berakhir dimasak dengan proses Kraft dengan kondisi sebagai berikut: $\mathrm{NaOH} \mathrm{10 \%}$ terhadap BKO (berat kering oven), $\mathrm{L}: \mathrm{W}=1: 5$ ( $\mathrm{L}=$ berat serpih, W=larutan pemasak), lama pemasakan 1 jam. Setelah dimasak, serpih direndam dalam air dingin 1 L selama 24 jam untuk mengoptimalkan sisa-sisa bahan pemasak dalam melunakkan serpih. Selanjutnya serpih dicuci sampai bebas alkali dan diblender untuk mendapatkan serbuk ukuran 30-40 mesh yang akan dianalisis bilangan kappa dan kadar holoselulosa.

\section{HASIL DAN PEMBAHASAN}

Pertumbuhan JPP P. chrysosporium (PC) sangat cepat (rapat) ditunjukkan pada hari ke-7 miselium sudah merata di seluruh substrat. Pada minggu ke- 2 sampai akhir inkubasi (45 hari), miselium semakin padat dan substrat hampir tidak terlihat (Gb. 1). Hal ini menunjukkan bahwa PC dapat beradaptasi dengan baik pada substrat pelepah salak dengan menggunakan nutrisi dari substrat. Ukuran serat yang kecil akan memperluas permukaan untuk membantu pertumbuhan miselium jamur. Niladevi dkk. (2007) menyatakan bahwa luas permukaan merupakan salah satu faktor penting yang mempengaruhi pertumbuhan jamur pada fermentasi kultur padat.
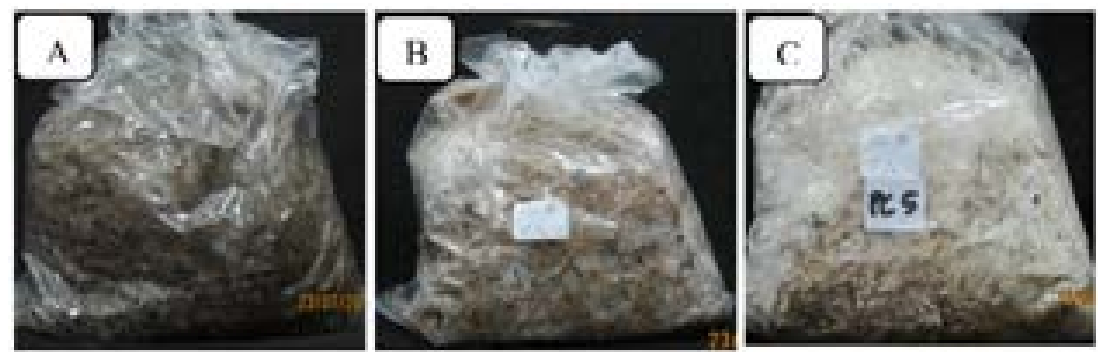

Gambar 1. Perbandingan P. crysopsporium pada Substrat Serat Pelepah Tanaman Salak (A. Kontrol, B : hari, $C: 45$ hari) 
Kemampuan JPP PC pada proses biopulping dapat diukur dari bilangan kappa dan kadar holoselulosa selama inkubasi. Setelah perlakuan dengan jamur pelapuk putih, maka dilanjutkan proses pemasakan dalam digester menggunakan $\mathrm{NaOH} \quad 10 \%$ untuk meningkatkan kembali degradasi lignin sampai mencapai bilangan Kappa. Bilangan Kappa menunjukkan pengukuran tidak langsung kadar lignin dalam pulp. Apabila bilangan Kappa tinggi menunjukkan kadar lignin masih tinggi dan begitu sebaliknya.
Hasil penelitian menunjukkan PC dapat menurunkan bilangan Kappa pulp hasil biopulping serat pelepah salak setelah inkubasi 45 hari dari 41,6\% menjadi 39,5\% bila dibandingkan kontrol (tanpa JPP) atau turun 5\% (Tabel 1). Hal ini selaras dengan penelitian Istikowati, 2010; Supriyanto, 2009; Singh, 2014). Penurunan ini ternyata belum memenuhi strandar bilangan Kappa menurut standar TAPPI dalam Biermann (1996) dimana standar bilangan Kappa antara 6 sampai 20.

Tabel 1. Hasil Analisis Bilangan Kappa dan Kadar Holoselulosa Pulp Pelepah Salak Setelah Biopulping Menggunakan JPP P. chrysosporium (PC)

\begin{tabular}{ccc}
\hline Perlakuan & Bilangan Kappa & Holoselulosa (\%) \\
\hline Kontrol & 41.6 & 66.09 \\
PC & 39.5 & 66.57 \\
\hline
\end{tabular}

Holoselulosa merupakan fraksi total dari karbohidrat dan salah satu penyusun dinding sel tanaman yang terdiri dari hemiselulosa dan selulosa. Selulosa merupakan komponen utama penyusun dinding sel tanaman yang berikatan $\beta-1,4$ glukosida dalam rantai lurus (Lynd et al. 2002; Daniel 2003). Kadar holoselulosa yang tinggi menggambarkan bahwa bubur kayu yang akan diperoleh dari proses pemasakan kayu akan tinggi juga. Tabel 1 menunjukkan bahwa kadar holoselulosa kontrol dan perlakuan hampir sama yaitu $66 \%$ dan kadar ini menunjukkan serat pelepah salak sangat baik sebagai bahan pulp karena kadar selulosanya lebih dari 65\% (Anonim, 1980).

\section{SIMPULAN}

JPP Phanerochaete chrysosporium dapat tumbuh bagus pada substrat serat pelepah salak untuk biopulping dan dapat menurunkan bilangan Kappa 5\% setelah 45 hari inkubasi tetapi kadar holoselulosa sama dengan control.

\section{SARAN}

Perlu dilakukan variasi lama inkubasi dan analisis kadar lignin, selulosa, serta hemiselulosa.

\section{UCAPAN TERIMA KASIH}

Penulis menyampaikan ucapan terima kasih kepada Direktorat Riset dan Pengabdian Masyarakat Direktorat Jenderal Penguatan Riset dan Pengembangan Kementerian Riset, Teknologi, dan Pendidikan Tinggi, atas biaya penelitian dengan nomor proyek:006/SP2H/LT/DRPM/II/2016, tanggal 17 Februari 2016.

\section{DAFTAR PUSTAKA}

Anonim, . 1980. Guideline for utilization and marketing of tropical wood species. Food and Agricultural Organization of the United Nation, Rome.

Ahmed. A, Gary M. Scott, Masood Akhtar and Gary C. Myers, 1998, Biokraft Pulping of Kenaf and its Bleachability, Preceeding North American 
Nonwood Fiber Symposium.

Akhtar. M., G. M. Scott , R. E. Swaney, and T. K. Kirk, 1992. Overview of Biomechanical and Biochemical Pulping Research, ACS Symposium Series, American Chemical Society, Washington, DC

Azhari. A., Falah. S., Nurjannah. L., Suryani, dan Bintang., M., 2014., Delignifikasi Batang Kayu Sengon oleh Trametes versicolor, Current Biochemistry Journal, Volume 1 (1): 1-10.

Bajpai, P., 2012, Biotechnology for Pulp and Paper Processing, DOI 10.1007/9781-4614-1409-4_7, Springer Science+Business Media. LLC

Bierman, C.J., 1996. Pulping and Papermaking. Academic Press. San Diego. California.

Daniel G. 2003. Microview of wood under degradation by bacteria and fungi. Wood deterioration and preservation. ACS Symposium series 845, Washington DC, USA.

Fatriasari. W., Anita. S.H., Falah. F., Adi. T.N., dan Hermiati. E., 2010, Biopulping Bambu Betung Menggunakan Kultur Campur Jamur Pelapuk Putih (Trametes versicolor, Pleurotus ostreatus dan Phanerochaete crysosporium), Berita Selulosa, Vol. 45, No. 2, Desember $2010: 44-56$.

Isroi, Millati, R., Syamsiah, S., Niklasson, C., Cahyanto, M.N., Lundquist, K., Taherzadeh, M.J., 2011. Biological Treatment of Lignocelulloses With White-Rot Fungi and Its Applications : A Review. Bioresources.com.

Istikowati, W. T., 2010, Pemanfaatan Jamur Phanerochaete chrysosporium burds Untuk Peningkatan Kwalitas Pulp Kayu Randu , Sains dan Terapan Kimia, Vol.4, No. 1 (Januari 2010), 51 $-58$

Kang, Kyu-Young; Sung, Jung-Suk; and
Kim, Dae-Young; 2007, Evaluation of White-rot Fungi for Biopulping of Wood, Mycobiology, Published online December 31, 2007. http://dx.doi. org/10.4489/MYCO.2007.35.4.205

Kirk, T.K., Burgess, R.R, and Koning, J.W. 1992. Use Fungi in Pulping Wood : An Overview of Biopulping Research. New York : Routledge, Chapman \& Hall, Chapter 7.

Kuntari, 2010. Pemanfaatan Limbah Mendong Sebagai Bahan Baku Kertas Seni. Jurnal Sains Materi Indonesia. Vol 11 No. 3 hal 188-194.

Lynd LR, Weimer PJ, van Zyl WH and Pretorius IS. 2002. Microbial cellulose utilization: fundamentals and biotechnology. Microbiol Mol Biol Rev. 66(3): 506-577.

Niladevi, K. Narayanan, R., Sukumaran, K., Prema, P., 2007, Utilization of rice straw for laccase Production by Streptomyces psammoticusin SolidState Fermentation. J Ind Microbiol Biotechnol, 34, 665-674

Nurjannah. I, dan Asngad. A., 2015, Pemanfaatan Limbah Bulu Ayam Dan Kulit Singkong Sebagai Bahan Pembuatan Kertas Seni Dengan Penambahan $\mathrm{NaOH}$ Dan Pewarna Alami, Skripsi. UMS.

Pratiwi dan Asngad. 2015. Pemanfaatan Limbah Bulu Ayam Dan Kulit Jagung Sebagai Bahan Pembuatan Kertas Seni Dengan Penambahan $\mathrm{NaOH}$ Dan Pewarna Alami, Skripsi, UMS.

Raharjo, W.P., Rudy S., Anindito P., M. Agus C., dan Triyono. 2016. Mechanical Properties of Untreated and Alkaline Treated Fibers from Zalacca Midrib Wastes. Sustainable Energy and Advanced Materials AIP Conf. Proc. 1717, 040018-1-040018-8; doi: $10.1063 / 1.4943461$ 
Riyanti, L.A.A. dan Asngad. A., 2015, Comparison of Differences Between Pemanfaatan Limbah Bulu Ayam Dan Kulit Kacang Tanah Sebagai Bahan Pembuatan Kertas Seni Dengan Penambahan NaOHDan Pewarna Alami, Skripsi, UMS.

Singh, pooja, 2014, effect of white rot fungi variation on The biopulping of oil palm trunk, universiti sains malaysia, disertasi

Srivilai, P., Chaiseana, W., Loutchanwoot, P., and Dornbundit, P., 2013, the Wood Degradation by Monokaryons (n) and Dikaryons (2n) of White Rot Fungus (Cambodian phellinus linteus), Journal of Biological Sciences 13 (3) : 131-138, ISSN 17273048.

Supriyanto, A., 2009, Manfaat Jamur Pelapuk Putih Phanerochaete chrysosporium L1 dan Pleurotus EB9 Untuk Biobleaching Pulp Kardus Bekas, Skripsi : IPB Bogor 